\title{
An Association Between Air Quality and COPD in Ahvaz, Iran
}

\author{
Mohammad Javad Mohammadi ${ }^{1}$; Hatam Godini ${ }^{2}$; Maimanat Tobeh Khak ${ }^{1}$; Seyed \\ Mohammad Daryanoosh ${ }^{2}$; Sina Dobaradaran ${ }^{3}$; Gholamreza Goudarzi ${ }^{1,4}$ \\ ${ }^{1}$ Department of Environmental Health Engineering, School of Public Health, Ahvaz Jundishapur University of Medical Sciences, Ahvaz, IR Iran \\ 2 Department of Environmental Health Engineering, School of Health, Lorestan University of Medical Sciences, Khorramabad, IR Iran \\ 3 Department of Environmental Health Engineering, Faculty of Health and The Persian Gulf Marine Biotechnology Research Center, the Persian Gulf Research Center, Bushehr \\ University of Medical Sciences, Bushehr, IR Iran \\ University of Medical Sciences, Bushehr, IR Iran
Environmental Technologies Research Center, Ahvaz Jundishapur University of Medical Sciences, Ahvaz, IR Iran \\ ${ }^{*}$ Corresponding author: Gholamreza Goudarzi, Department of Environmental Health Engineering, School of Public Health, Ahvaz Jundishapur University of Medical Sciences, Ahvaz, \\ IR Iran. Tel: 98-9163087159, Fax: +98-6113361544, E-mail: ghgoodarzi@ajums.ac.ir, rgoodarzy@gmail.com
}

Received: August 8, 2014; Revised: October 15, 2014; Accepted: December 24, 2014

\begin{abstract}
Context: Ahvaz, capital city of Khuzestan province, with a population of more than 1 million people is very famous in standpoint of air pollution. Nitrogen dioxide is emitted from vehicles and industries which can have short and long term effects on citizens.

Evidence Acquisition: Data were taken from Ahvaz Department of Environment (ADoE). Stations were Naderi, Behdasht Ghadim, Havashenasi, and Mohitzist. The COPD attributed to nitrogen dioxide in Ahvaz city, Iran, in 2011 were calculated by utilizing relative risk and baseline incidence related to health end point nitrogen dioxide. Data were analyzed by SPSS ver 16.

Results: The highest and lowest annually average nitrogen dioxide concentrations during 2011 were 70 and $21 \mu \mathrm{g} / \mathrm{m}^{3}$, respectively. The Bureau of Meteorology "Havashenasi" and head office of ADoE "Mohitzist" had the highest and the lowest nitrogen dioxide concentrations during 2011, respectively. Approximately 4\% of the hospital admission for COPD happened when the nitrogen dioxide concentration was > $10 \mu \mathrm{g} / \mathrm{m}^{3}$. Low percentage of the observed health endpoints was associated with low concentration of measured nitrogen dioxide.

Conclusions: Using alternative energy sources, such as solar cooking and electrical heating is effective, as is using fuels such as kerosene or coal rather than biomass. Higher relative risk value can depict mismanagement in urban air quality. The lower level of relative risk value may be achieved if some control strategies for reducing nitrogen dioxide emission are used.
\end{abstract}

Keywords:Air Pollutants; Human; Health; Nitrogen Dioxide

\section{Context}

Air pollution encompasses gaseous pollutants and particles. In another point of view air pollution can be classified into anthropogenic and biogenic. Anthropogenic air pollution is considered to be a serious public health problem and can be harmful to human health and welfare (1). Approximately $80 \%$ of people 65 years and over have one or more chronic diseases and about $50 \%$ of this group have activity limitations (2). Chronic obstructive pulmonary disease (COPD), also known as chronic obstructive lung disease (COLD), and chronic obstructive airway disease (COAD), among others, is a type of obstructive lung disease characterized by chronically poor airflow. It typically worsens over time. The main symptoms include shortness of breath, cough, and sputum production (3-5). Most people with chronic bronchitis have $\operatorname{COPD}(6,7)$. Tobacco smoking is the most common cause of COPD, with a number of other factors, such as air pollution and genetics playing a smaller role (8). In the developing world, one of the common sources of air pollution is from poorly vented stoves used for cooking and heating. Long-term exposure to these irritants causes an inflammatory response in the lungs resulting in narrow- ing of the small airways and the breakdown of lung tissue known as emphysema $(3,9)$. Advanced COPD leads to corpulmonale (high pressure on the lung arteries, which strains the right ventricle of the heart) and leads to symptoms of leg swelling and bulging neck veins (9-11). Chronic obstructive pulmonary disease is more common than any other lung disease as a cause of corpulmonale (10). It often occurs along with a number of other conditions, due in part to share risk factors (8). These conditions include: ischemic heart disease, high blood pressure, diabetes mellitus, muscle wasting, osteoporosis, lung cancer, anxiety disorder and depression (8). In those with a severe disease, a feeling of always being tired is common (7). Fingernail clubbing is not specific to COPD and should prompt investigations for an underlying lung cancer (12). Chronic obstructive pulmonary disease can be prevented by reducing exposure to the known causes (9). An acute exacerbation (a sudden worsening of symptoms) is commonly triggered by infection or environmental pollutants, or sometimes by other factors, such as improper use of medications $(13,14)$. Infections appear to be the cause of 50 to $75 \%$ of the cases, with bacteria in

Copyright (C) 2015, Ahvaz Jundishapur University of Medical Sciences. This is an open-access article distributed under the terms of the Creative Commons Attribution-NonCommercial 4.0 International License (http://creativecommons.org/licenses/by-nc/4.0/) which permits copy and redistribute the material just in noncommercial usages, provided the original work is properly cited. 
$25 \%$, viruses in $25 \%$, and both in $25 \%$. Environmental pollutants include both poor indoor and outdoor air quality (14-16). Exposure to personal smoke and secondhand smoke increases the risk $(14,17)$. Cold temperature may also play a role, with exacerbations occurring more commonly in winter (18). Both indoor and outdoor air quality can be improved, which may prevent COPD or slow the worsening of existing disease (17). This may be achieved by public policy efforts, cultural changes, and personal involvement (9). A number of developed countries have successfully improved outdoor quality through regulations. This has resulted in improvements of the lung function of their populations (17). Those with COPD may experience fewer symptoms if they stay indoors on days when outdoor air quality is poor (9). Results from the worldwide studies showed that COPD affects 329 million people or nearly $5 \%$ of the population. In 2013, it ranked as the fourth-leading cause of death, killing over 3 million people (19). The number of deaths is projected to increase due to higher smoking rates and an aging population in many countries (20). It resulted in an estimated economic cost of \$2.1 trillion in 2013 (21). Results showed that a significant increase in hospital admission for COPD, cardiovascular disease, ischemic heart disease and myocardial infarction was attributed to the increase in the nitrogen dioxide $\left(\mathrm{NO}_{2}\right)$ concentration (22). In another study which was conducted in Taiwan, there was an association between the $\mathrm{NO}_{2}$ levels and in hospital admission in patients suffered from ischemic stroke, COPD and asthma exacerbation (23). Another study has shown associations between hospital admissions for cardiovascular diseases and CODP attributed to an increase in the $\mathrm{NO}_{2}$ concentrations (24). Dockery et al. in a cohort study has shown an adverse health impact of long-term air pollution exposure in the six U.S. cities. This study demonstrated that chronic exposure to air pollutants is independently related to cardiovascular mortality (25). In similar work, Mohammadi et al. studied the association between COPD and $\mathrm{NO}_{2}$ levels in the Ahvaz in 2009 (26). Also, Goudarzi et al. studied the association between COPD and $\mathrm{NO}_{2}$ levels in the Tehran in 2009 (27). Zalaghi et al. studied the association between COPD and $\mathrm{NO}_{2}$ levels in the Ahvaz, Bushehr and Kermanshah in 2010 (28).

From past to now, Ahvaz has been well-known due to industries as well as environmental pollution. In the last decade, an anthropogenic source of air pollution (dust storm) has joined to other environmental problems (29). Physical, chemical and biological characteristics of dust storm and also the identification of hazardous air pollutants, such as BTEX have been well-documented (29-32). The social impact of dust storm on Ahvaz citizens was also evaluated (33). Furthermore, health effects of air pollution attributed to $\mathrm{NO}_{2}$, ozone and particulate matter were reported in most megacities of Iran, particularly Ahvaz. It should be noted that ahvaz has suffered from dust storm recently (38).Therefore, we decided to assess health effects of NO2 which has not studied yet $(1,29,33,34)$.
The purpose of this study was to assess the COPD attributed to the $\mathrm{NO}_{2}$ exposure on human health in Ahvaz city (located in south-western Iran) during 2011-2012.

\section{Evidence Acquisition}

In this epidemiological study, sampling and data collection were done by Ahvaz Department of Environment. Nitrogen dioxide data were analyzed using the Excel software and AirQ model. The AirQ software was proved to be a valid and reliable tool to estimate the potential shortterm effects of air pollution, predicts health endpoints attributed to criteria pollutants, and allows the examination of various scenarios in which emission rates of pollutants are varied (33). This study was conducted to assess the potential effects of nitrogen dioxide exposure on human health. Chronic obstructive pulmonary disease attributed to nitrogen dioxide in Ahvaz city at 2011 was calculated based on the utilizing relative risk (RR) and attributable proportion. Geographical features of Ahvaz: Ahvaz city, with a population of 1 million approximately, with an area of $8152 \mathrm{~km}^{2}$, the capital city of Khuzestan Province is located between 48 degree to $49^{\circ} 29^{-}$east of Greenwich meridian and between 31 degrees and $45 \mathrm{~min}$ utes to the north of the equator (1). Sampling was performed for 24 hours in 4 stations. In this study $4 \times 365$ samples of Ahvaz's air was taken and collected. Data was taken from Ahvaz Department of Environment (ADoE). Stations were Downtown "Naderi”, Old School of Public Health "Behdasht Ghadim", Bureau of Meteorology "Havashenasi" and Head office of ADoE "Mohitzist". To make the file, the following steps were taken in a row: these data were in volumetric base. Health effects are being related to the mass of pollutants inhaled and this is why the AirQ model was on gravimetric basis. Therefore, there was an inconvenience between AirQ model and ADoE data. Conversion between volumetric and gravimetric units include: correction of temperature and pressure (when the temperature and pressure change the volume of the gas changes, but it still contains the same mass of material), conformity of the unit with the model, coding, processing (averaging) and filtering are implemented for solving such problem. The daily mean was calculated based on codification, condition modification and primary and secondary filtering. Thereafter, 24 hour means were calculated for nitrogen dioxide pollutant. To estimate the health impact attributed to the exposure of air pollution on the target population, the AirQ model was used which estimatesthis impactfor specific air pollutants on a resident population in a certain area and period.

\subsection{Data Analysis}

We determine the extent of health effect based on the relative risk and attributable proportion attributed to nitrogen dioxide. The RR is a measure of association between a disease or condition and a factor under study. It is calculated by dividing the incidence rate among those 
exposed to the factor by the incidence rate among those not exposed to the factor (35).

$\mathrm{RR}=$ Incidence in the exposed population / Incidence in the non-exposed population

The population prevented fraction refers to situations where exposure to a factor is protective. Data capture was collected for criteria air pollutants. Attributable proportion is a fraction of health consequences in a specific population that can be attributed to a specific air pollutant exposure with this notion that there is a proven causative correlation between health consequences and air pollutant exposure. We have use default model that attribute the COPD cases to exposure to nitrogen dioxide and remove another factor effects. In addition to total cases attributable to exposure to nitrogen dioxide, we could estimate the distribution of cases attributable in terms of concentration intervals of pollutant. Having relative risk in a specific concentration level of the pollutant and rate in an unexposed population, we can obtain extras rate (I $+(\mathrm{c})$ ) and the number of extras $(\mathrm{N}+(\mathrm{c}))$ in a groups exposed (36):

$$
(\mathrm{RR}(\mathrm{c}-1))=\mathrm{I}+(\mathrm{c}) \times \mathrm{I}_{\mathrm{Ne}} \mathrm{P}_{(\mathrm{c})}
$$

All the above-mentioned equations are based on the assumption that the estimation used in this analysis has been controlled regarding all probable confounders. Putting confidence intervals of the RR estimation in the equation, we will have upper and lower limits of attributed part and the range of cases attributable to expected exposure. Indeed, practically uncertainty of the effect (and the range of estimated effects) is larger due to exposure assessment errors and non-statistical uncertainties of concentration-response function. Thus, we may obtain the increase in death toll due to increase in the concentration of pollutants. Sampling and data collectionwere done atADoE and the data were analyzed using the Excel software and AirQ model. The health impact attributable to the exposure of air pollution on the target population was estimated using the AirQ model, which estimates this impactfor specific air pollutants on a resident population in a certain area and period (Figure 1).

\section{Results}

According to the research findings, the highest and the lowest annual average nitrogen dioxide concentrations during 2011-2012 were 70 and $21 \mu \mathrm{g} / \mathrm{m}^{3}$, respectively. The Bureau of Meteorology "Havashenasi" and Head office of ADoE "Mohitzist" had the highest and the lowest nitrogen dioxide concentrations during 2011-2012, respectively. The primary standard of nitrogen dioxide according to National Ambient Air Quality Standard (NAAQS) is 100 ppb as hourly averaging time (39). World Health Organization (AQG WHO) has recommended 40 and $200 \mu \mathrm{g} / \mathrm{m}^{3}$ as annual and hourly averages of nitrogen dioxide concentrations, respectively $(34,39)$. Table 1 shows that annual average of nitrogen dioxide concentration in Ahvaz was $31 \mu \mathrm{g} / \mathrm{m}^{3}$ in 2011, which is lower than AQG WHO and also much lower than the NAAQS standards. The annual average, summer average, winter average and 98 percentile of nitrogen dioxide concentrations in these stations have been presented in Table 1. According to Figure 2 in winter nitrogen dioxide concentrations were the maximum concentration as compared to other seasons during this year. This can result from pollutants produced in combustion processes which can occur mostly in transportation, power stations, heating plants and industrial processes. The major sources of nitrogen dioxide that can increase the risk of developing COPD are resulting from anthropogenic source of air pollution such as road traffic, stationary combustion and industrial processes. Ahvaz has been well-known due to its industries as well as petroleum steel and power stations. In the last decade, an anthropogenic source of air pollution has joined to other environmental problems.

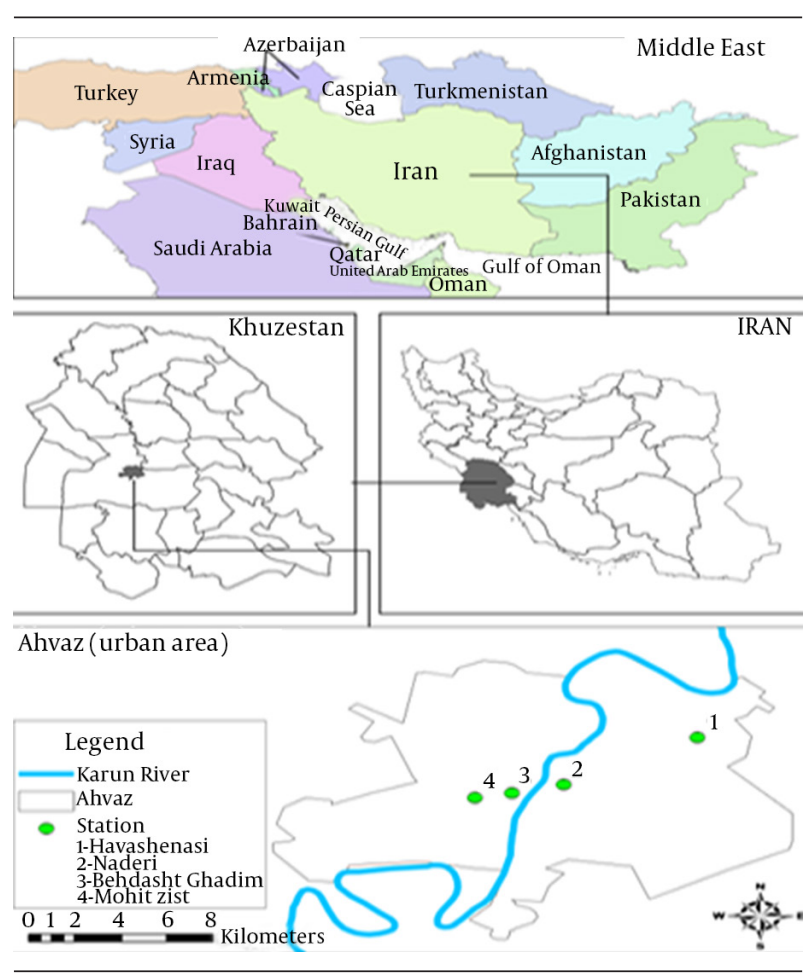

Figure 1. Location of the Study Area and Sampling Station in the Khuzestan Province (Ahvaz City), in the South West of Iran (37)

Table 1. The Highest and Lowest Concentrations of Nitrogen Dioxide $\left(\mu \mathrm{g} / \mathrm{m}^{3}\right)$ Corresponding to Stations

\begin{tabular}{lccc}
\hline Stations/Parameter & $\begin{array}{c}\text { Average } \\
\text { Ahvaz }\end{array}$ & $\begin{array}{c}\text { Lowest } \\
\text { Stations } \\
\text { (Mohitzist) }\end{array}$ & $\begin{array}{c}\text { Highest Sta- } \\
\text { tions (Havash- } \\
\text { enasi) }\end{array}$ \\
\hline Annual mean & 31 & 21 & 70 \\
Summer mean & 12 & 9 & 15 \\
Winter mean & 50 & 31 & 81 \\
98 percentile & 148 & 61 & 286 \\
\hline
\end{tabular}




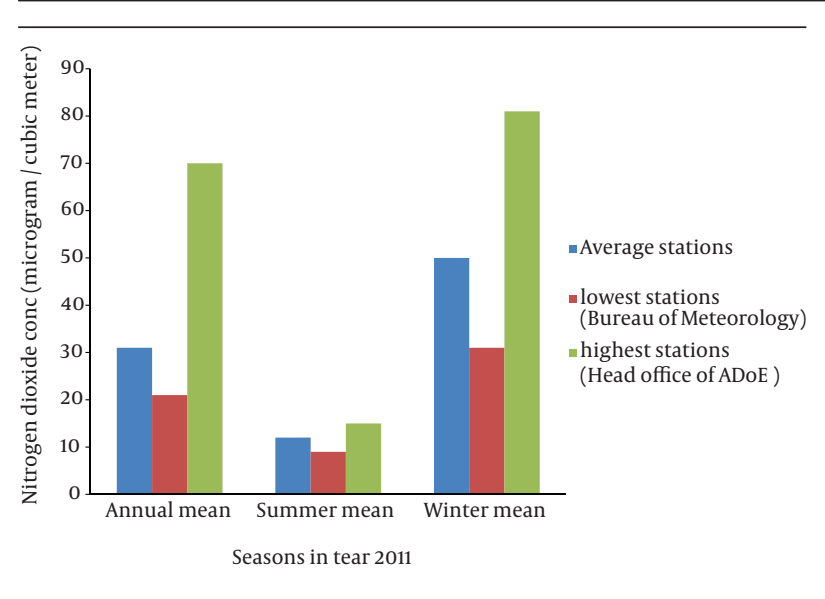

Figure 2. Relationship Between Nitrogen Dioxide Concentration and Seasons in Year 2011

Table 2. Relative Risks, Attributable Proportions and Number of People Suffering From Chronic Obstructive Pulmonary Disease Due to Nitrogen Dioxide Exposure

\begin{tabular}{lccc}
\hline $\begin{array}{l}\text { Indicator/ } \\
\text { Estimate }\end{array}$ & RR(Medium) & AP,\% & $\begin{array}{c}\text { Attributable Excess } \\
\text { Cases (Persons) }\end{array}$ \\
\hline Down & 1.0004 & 0.092 & 2.4 \\
Mediocre & 1.0038 & 0.9561 & 9.8 \\
Up & 1.0094 & 1.1694 & 22.5 \\
\hline
\end{tabular}

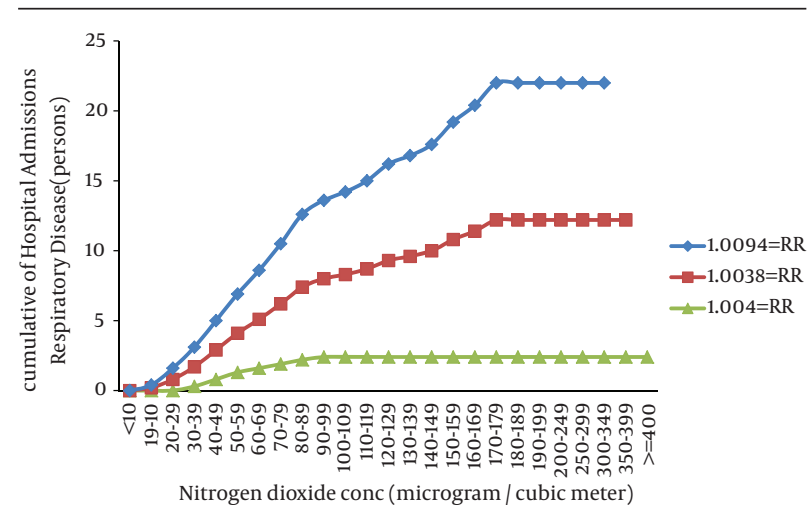

Figure 3. Relationship Between Cumulative Numbers of Hospital Admission for Chronic Obstructive Pulmonary Disease Versus Nitrogen Dioxide Concentration

In field of morbidity, hospital admission of COPD versus nitrogen dioxide concentration has shown in Table 2. Estimated number of excess cases attributed to nitrogen dioxide for hospital admission of COPD at lower, central and higher confidence interval of RR was 3, 10 and 23, respectively. The lower level of RR may imply to the improvement of urban air quality by implementing of emission control strategies. Therefore, the higher RR can depict mismanagement in urban air quality. Central $\mathrm{RR}$ is corresponded to 10 as predicted number of excess cases and it can be a good representative of real situation in standpoint of nitrogen dioxide health effects. As Fig- ure 3 indicates, despite the relative risk of health effects of nitrogen dioxide concentrations below $30 \mu \mathrm{g} / \mathrm{m}^{3}$ due to lack of contact with the population concentration is zero. In other words, no one day in 2011 has been reaches the nitrogen dioxide concentration below $30 \mu \mathrm{g} / \mathrm{m}^{3}$. Rising trend of cases hospital admission of COPD with increasing concentrations of Nitrogen dioxide in 30-170 $\mu \mathrm{g}$ / $\mathrm{m}^{3}$ has a uniform trend.

\section{Conclusions}

In recent decades, air pollution is considered as a serious threat to the environment, quality of life and health of people. This study aimed to estimate the effects of exposure to nitrogen dioxide air pollution on the risk ofdevelopingCOPD using the AirQ model in Ahvaz, Iran. Figures 2 to 3 have illustrated nitrogen dioxide concentrations versus related health endpoint and average concentrations during seasons. As the results showed, three ranges of RR based on model's default were considered for assessing health effects of nitrogen dioxide. Furthermore, BI values were also taken from default of the model. Also, results showed that winter and summer had the highest and the lowest nitrogen dioxide concentrations during 2011-2012, respectively. In Ahvaz population study on one million people and base on BI of 497 per 100,000 people in year $2011,73 \%$ of the COPD cases occurred in days with pollutant not exceeding $70 \mu \mathrm{g} / \mathrm{m}^{3}$.

In similar work Goudarzi et al. they exploited the AirQ model to estimate the nitrogen dioxide hygienic effects on potential COPD in Tehran (capital of Iran). Based on their results, almost $4.4 \%$ of all cases of whole COPD are attributed to the nitrogen dioxide concentrations greater than $30 \mu \mathrm{g} / \mathrm{m}^{3}$ (28). Moreover, Mohammadi et al. report that approximately 3 percent of hospital admission for COPD happened when the nitrogen dioxide concentration was over $20 \mu \mathrm{g} / \mathrm{m}^{3}(26)$.

The mortality rate due to COPD in Wisconsin was reported by $88 \%$ between 1980 and 2000 (40). Zalaghi et al. In 2010 in survey of health effects of air pollution in Ahvaz, Bushehr and Kermanshah report that approximately 3.5 percent in Ahvaz, 2.1 percent in Kermanshah and 1.1 percent of COPD attributed to nitrogen dioxide in people (28). The increase in the developing world between 1970 and the 2000s is believed to be related to increasing rates of smoking in this region, an increasing population and an aging population due to less death from other causes, such as infectious diseases (8). The global numbers are expected to continue increasing as risk factors remain common and the population continues to get older (41). Between 1990 and 2010 the number of deaths from COPD has decreased slightly from 3.1 million to 2.9 million (42). Overall, it is the fourth-leading cause of death (8). In some countries, mortality rate has decreased in men but has increased in women (43). This is most likely due to rates of smoking in women and men becoming more similar COPD is more common in older people; it affects $34-200$ 
out of 1000 people older than 65 years, depending on the population looked at $(3,6,44)$. In England, an estimated 0.84 million people (of 50 million) have a diagnosis of COPD; translating into approximately one person in 59 receiving a diagnosis of COPD at some point in their lives. In the most socioeconomically deprived parts of the country, one in 32 people were diagnosed with COPD, compared with one in 98 in the most affluent areas (45). In the United States approximately $6.3 \%$ of the adult population, totaling approximately 15 million people, has been diagnosed with COPD (46). 25 million people may have COPD if currently undiagnosed cases are included (47). In 2011, there were approximately 730,000 hospitalizations in the United States for COPD (48). The major limitations of this study is lack of databases and indicators amounts that for solve this lack we used the values of the WHO (Middle East) for calculated health effects attribute nitrogen dioxide. Therefore, estimating the health effects of air pollutants actually requires epidemiologic studies for accurate calculation of RRs and BIs. Accordingly, costeffective measures and management schemes should be considered to abate air pollution concentrations and/or reduce the exposure of general population to air pollutants. Finally, the survey results showed that implementation of basic actions to the control of $\mathrm{NO}_{2}$ entering into the stratosphere by decreasing consume gasoil fuel in industries and development of green space is essential.

Based on the results of this study, $4 \%$ of hospital admissions for COPD were attributed to respiratory nitrogen dioxide in people. High percentage of the observed health endpoints was associated with high concentration of measured nitrogen dioxide. Although the results of this study are in line with results of other researches around the world, the geographic, demographic, and climate characteristics are different, there is still high need to further studies to specify local RR and BI. Using alternative energy sources, such as solar cooking and electrical heating is effective, as is using fuels such as kerosene or coal rather than biomass. Considering that little prerequisite building, calculated times diseases attributable to air pollution and health effects of air pollutants estimated, there are the epidemiological indicators, these indicators to calculate the experts are recommended.

\section{Acknowledgements}

We thankfully acknowledge the Deputy of Research Affairs at the Ahvaz Jundishapur University of Medical Sciences for their financial and technical support for this research.

\section{Authors' Contributions}

Study concept, design and critical revision of the manuscript for important intellectual content: Mr Mohammadi processed excel data, Dr Goudini revised manuscript, Miss Tobeh khak collected data, Mr Daryanoosh worked on model, Dr Dobaradaran added some professional points in it and Dr Goudarzi combined all together and finalized the manuscript.

\section{Funding/Support}

This study was supported by Ahvaz Jundishapur University of Medical Sciences.

\section{References}

1. Goudarzi G, Mohammadi M, Ahmadi Angali K, Mohammadi B, Soleimani Z, Babaei A, et al. Estimation of Number of Cardiovascular Death, Myocardial Infarction and Chronic Obstructive Pulmonary Disease (COPD) from NO2 Exposure using Air Q Model in Ahvaz City During 2009. IJHE. 2013;6(1):91-102.

2. Noroozi-tabrizi K, Abedi H, Maddah-Sayyedbagher S, Mohammadi E, Babaei G. Evaluation model of community-based care system for the elderly in Tehran.J Iranian Rehab. 2003;6(21):36-42.

3. Fishman AP. One hundred years of chronic obstructive pulmonary disease. Am J Respir Crit Care Med. 2005;171(9):941-8.

4. Gruber P. the Acute Presentation of Chronic Obstructive Pulmonary Disease in the Emergency Department: A Challenging Oxymoron. J Eme Med Pract. 2008;10(11):1-12.

5. Nathell L, Nathell M, Malmberg P, Larsson K. COPD diagnosis related to different guidelines and spirometry techniques. Respir Res. 2007;8:89.

6. Longo D, Fauci A, Kasper D, Hauser S, Jameson J, Loscalzo J. Harrison's Principles of Internal Medicine, 18th Edition.: Mcgraw-hill; 2011.

7. O'Donnell DE. Hyperinflation, dyspnea, and exercise intolerance in chronic obstructive pulmonary disease. Proc Am Thorac Soc. 2006;3(2):180-4.

8. Decramer M, Janssens W, Miravitlles M. Chronic obstructive pulmonary disease. Lancet. 2012;379(9823):1341-51.

9. Rabe KF, Hurd S, Anzueto A, Barnes PJ, Buist SA, Calverley P, et al. Global strategy for the diagnosis, management, and prevention of chronic obstructive pulmonary disease: GOLD executive summary. Am J Respir Crit Care Med. 2007;176(6):532-55.

10. Weitzenblum E, Chaouat A. Cor pulmonale. Chron Respir Dis. 2009;6(3):177-85.

11. Wilkins LW. Professional Guide to Diseases.: Wolters Kluwer Health/Lippincott Williams \& Wilkins; 2009.

12. Stoller JK, Michota FA, Mandell BF, Foundation CC. The Cleveland Clinic Foundation Intensive Review of Internal Medicine.: Lippincott Williams \& Wilkins; 2009.

13. Brulotte CA, Lang ES. Acute exacerbations of chronic obstructive pulmonary disease in the emergency department. Emerg Med Clin North Am. 2012;30(2):223-47.

14. Jindal SK, Shankar PS, Raoof S, Gupta D. Textbook of Pulmonary and Critical Care Medicine Vols 1 and 2.: Jaypee Brothers, Medical Publishers; 2011.

15. Qaseem A, Wilt TJ, Weinberger SE, Hanania NA, Criner G, van der Molen T, et al. Diagnosis and management of stable chronic obstructive pulmonary disease: a clinical practice guideline update from the American College of Physicians, American College of Chest Physicians, American Thoracic Society, and European Respiratory Society. Ann Intern Med. 2011;155(3):179-91.

16. Lotvall J, Busse W. Advances in Combination Therapy for Asthma and COPD.: Wiley; 2011.

17. Pirozzi C, Scholand MB. Smoking cessation and environmental hygiene. Med Clin North Am. 2012;96(4):849-67.

18. Mahler DA. Mechanisms and measurement of dyspnea in chronic obstructive pulmonary disease. Proc Am Thorac Soc. 2006;3(3):234-8.

19. W.H.O . The 10 leading causes of death in the world 2000 and 2011. World Health Organization; 2013.

20. Mathers CD, Loncar D. Projections of global mortality and burden of disease from 2002 to 2030. PLoS Med. 2006;3(11).

21. Lomborg B. Global Problems, Smart Solutions: Costs and Benefits.: Cambridge University Press; 2013.

22. Barnett AG, Williams GM, Schwartz J, Best TL, Neller AH, Petroeschevsky AL, et al. The effects of air pollution on hospitalizations 
for cardiovascular disease in elderly people in Australian and New Zealand cities. Environ Health Perspect. 2006;114(7):1018-23.

23. Tsai SS, Goggins WB, Chiu HF, Yang CY. Evidence for an association between air pollution and daily stroke admissions in Kaohsiung, Taiwan. Stroke. 2003;34(11):2612-6.

24. Yang CY, Chen YS, Yang CH, Ho SC. Relationship between ambient air pollution and hospital admissions for cardiovascular diseases in kaohsiung, taiwan. J Toxicol Environ Health A. 2004;67(6):483-93.

25. Dockery DW, Pope C3, Xu X, Spengler JD, Ware JH, Fay ME, et al. An association between air pollution and mortality in six U.S. cities. N Engl J Med.1993;329(24):1753-9.

26. Mohammadi MJ. . Studied hygienic effects of air pollution in town Ahvaz in 2009 with model Air Q. : Ahvaz Jundishapur University of Medical Sciences; 2009.

27. Goudarzi G. . Quantification of health effects of air pollution in Tehran and determining the impact of a comprehensive program to reduce air pollution in Tehran on the third axis. : ehran University of Medical Sciences; 2007.

28. Zalaghi E. . Survey of health Effects of Air Pollution Ahvaz, Bushehr and Kermanshah with Use of AIRQ Model [Dissertation]. : Islamic Azad University, Science and Research Branch, Ahvaz; 2010

29. Soleimani Z, Goudarzi G, Naddafi K, Sadeghinejad B, Latifi SM Parhizgari N, et al. Determination of culturable indoor airborne fungi during normal and dust event days in Ahvaz, Iran. Aerobiologia. 2013;29(2):279-90.

30. Goudarzi G, Geravandi S, Vosoughi M, javad Mohammadi M sadat Taghavirad S. Cardiovascular deaths related to Carbon monoxide Exposure in Ahvaz, Iran. Iranian J Health Safety Environ. 2014;1(3):126-31.

31. Goudarzi G, Mohammadi M, Ahmadi Angali K, Neisi AK, Babaei A, Mohammadi B, et al. Estimation of Health Effects Attributed to NO2 Exposure Using AirQ Model. J Arch Hyg Sci. 2012;1(2):59-66.

32. Goudarzi G, Zallaghi E, Saki A, Neisi AK, Ahmadi Angali K, Moham madi MJ. Cardiopulmonary Mortalities and Chronic Obstructive Pulmonary Disease Attributed to Ozone Air Pollution. J Arch Hyg Sci. 2013;2(2):62-7.

33. Zallaghi E, Goudarzi G, Geravandi S, Mohammadi MJ, Vosoughi Niri M, Vesyi E. Estimating the prevalence of cardiovascular and respiratory diseases due to particulate air pollutants in Tabriz air. Scientfic J Ilam University of Medi Sci. 2014;22(1):84-91.

34. Taghavirad SS, Davar H, Mohammadi MJ. The a study on concentration of BETX vapors during winter in the department of ports and shipping located in one of the southern cities of Iran. Inte J CurLife Sci. 2014;4(9):5416-20.
35. Kaelin MA, Bayona M. Attributable risk applications in epidemiology. College Entrance Examination Board. 2004:6-7.

36. Rockhill B, Newman B, Weinberg C. Use and misuse of population attributable fractions. Am J Public Health. 1998;88(1):15-9.

37. Goudarzi G, Shirmardi M, Khodarahmi F, Hashemi-Shahraki A Alavi N, Ankali KA, et al. Particulate matter and bacteria characteristics of the Middle East Dust (MED) storms over Ahvaz, Iran. Aerobiologia. 2014;30(1):1-12.

38. US Environmental Protection Agency. National Ambient Air Quality Standards (NAAQS): for air pollutant. US Environmental Protection Agency; 2010.

39. W.H.O.WHO Air quality guidelines for particulate matter, ozone, nitrogen dioxide and sulfur dioxide: Summary of risk assessment, Global update. World Health Organization; 2005.

40. Vos T, Flaxman AD, Naghavi M, Lozano R, Michaud C, Ezzati M, et al. Years lived with disability (YLDs) for 1160 sequelae of 289 diseases and injuries 1990-2010: a systematic analysis for the Globa Burden of Disease Study 2010. Lancet. 2012;380(9859):2163-96.

41. Vestbo J, Hurd SS, Agusti AG, Jones PW, Vogelmeier C, Anzueto A et al. Global strategy for the diagnosis, management, and prevention of chronic obstructive pulmonary disease: GOLD executive summary. Am J Respir Crit Care Med. 2013;187(4):347-65.

42. Lozano R, Naghavi M, Foreman K, Lim S, Shibuya K, Aboyans V, et al. Global and regional mortality from 235 causes of death for 20 age groups in 1990 and 2010: a systematic analysis for the Globa Burden of Disease Study 2010. Lancet. 2012;380(9859):2095-128.

43. Rycroft CE, Heyes A, Lanza L, Becker K. Epidemiology of chronic obstructive pulmonary disease: a literature review. Int J Chron $\mathrm{Ob}$ struct Pulmon Dis. 2012;7:457-94.

44. Torres M, Moayedi S. Evaluation of the acutely dyspneic elderly patient. Clin Geriatr Med. 2007;23(2):307-25.

45. Simpson CR, Hippisley-Cox J, Sheikh A. Trends in the epidemiology of chronic obstructive pulmonary disease in England: a national study of 51804 patients. BrJ Gen Pract. 2010;60(576):277-84

46. Centers for Disease C, Prevention.. Chronic obstructive pulmonary disease among adults--United States, 2011. MMWR Morb Mortal Wkly Rep. 2012;61(46):938-43.

47. National Heart Lung, Blood Institute . Morbidity and mortality: 2009 chart book on cardiovascular, lung, and blood diseases. Rockville (MD): US Department of Health and Human Services, National Institutes of Health. 2004

48. Torio CM, Andrews RM. Healthcare Cost and Utilization Project (HCUP) Statistical Briefs. Rockville (MD): 2006. National Inpatient Hospital Costs: The Most Expensive Conditions by Payer, 2011: Statistical Brief \#160. 